\title{
Torsional conjugate eye movements induced by pupillary light stimulation
}

\author{
MORRIS B. BENDER ${ }^{1}$ AND MORTON CORIN \\ From the Department of Neurology, The Mount Sinai School of Medicine, \\ of the City University of New York, New York, U.S.A.
}

SYNOPSIS A patient with a brain-stem mass and some evidence of brain-stem dysfunction showed $\frac{\widetilde{D}}{\triangle}$ torsional conjugate eye movements after eyelid opening in an illuminated environment, also on pupillary light stimulation. The response appeared after a latency period of 1-2 s, and occurred on stimulation of either the right or left eye. The ocular torsion was always bilateral and often conjugate. The phenomenon, however, varied in the extent, the direction and the symmetry of movement in $\vec{\omega}$ the two eyes. It is probable that the phenomenon described was due to a disorder in the central, brain-stem mechanism, but the exact anatomical site and physiology are at present imprecise.

In the normal subject, light stimulation of one eye causes bilateral pupillary constriction. This response, however, is often associated with a tendency for the eyelids to close and occasionally both globes may tend to move slightly upward. This triple effect-that is, pupillary constriction, eyelid closure, and upward movement of the globes-is bilateral and greater on the side of light stimulation. The same occurs during corneal stimulation, except that the bilateral eyelid closure and upward eye movements are more vigorous, while the pupillary constrictions are minimal. Other situations in which there is transient eyelid closure associated with spontaneous eye movements, are spontaneous blinking, blinking induced by loud sound or noise (cochleo-palpebral reflex), or that caused by eye irritants such as smoke or ammonia. These are five examples of transient eye closure or blinks associated with slight upward movement of the globe and even pupillary constriction as listed in the Table. The pupillary constriction in man is rarely noticeable. In the monkey every type of blink is associated with a conspicuous upward movement of the globe and good pupillary constriction.

Examples of prolonged closure of the eyes are

\footnotetext{
1 Reprint requests: Dr. M. B. Bender, Department of Neurology, The Mount Sinai School of Medicine, Fifth Avenue and 100th Street, New York, New York 10029, U.S.A.
}

TABLE

CONDITIONS IN WHICH THE TRIAD OF ASSOCIATED OCULOMOTOR EFFECTS OCCUR

\begin{tabular}{|c|c|c|c|}
\hline Condition & $\begin{array}{l}\text { Eyelid } \\
\text { closure }\end{array}$ & $\begin{array}{l}\text { Upward } \\
\text { movement } \\
\text { of globes }\end{array}$ & $\begin{array}{l}\text { Pupillary } \\
\text { constric } \\
\text { tion } 2\end{array}$ \\
\hline 1. Light stimulation & Blink & Minimal & Maximale \\
\hline 2. Corneal stimulation & Blink & Minimal & Minimal \\
\hline 3. Auditory stimulation & Blink & Minimal & Minimal \\
\hline 4. Irritation of eyes & Blink & Present & Median \\
\hline 5. Spontaneous blink & Blink & Minimal & Minimal \\
\hline $\begin{array}{l}\text { 6. Voluntary eye } \\
\text { closure }\end{array}$ & $\begin{array}{c}\text { Continual } \\
\text { closure }\end{array}$ & Conspicuous & Slight \\
\hline 7. Sleep & $\begin{array}{c}\text { Continual } \\
\text { closure }\end{array}$ & Conspicuous & Median \\
\hline 8. Anaesthesia & $\begin{array}{c}\text { Continual } \\
\text { closure }\end{array}$ & Conspicuous & $\begin{array}{l}\text { Depends } \\
\text { on stage } \\
\text { of } \\
\text { anaes- } \\
\text { thesia }\end{array}$ \\
\hline 9. Stupor & $\begin{array}{c}\text { Continual } \\
\text { closure }\end{array}$ & Conspicuous & Median \\
\hline $\begin{array}{l}\text { 10. Electric stimulation } \\
\text { of brain-stem or } \\
\text { cerebral cortex }\end{array}$ & $\begin{array}{c}\text { Continual } \\
\text { closure }\end{array}$ & Variable & Variable \\
\hline
\end{tabular}

listed from 6 to 10 in the Table. During voluntary closure of the eyes the globes are elevated above 의 the horizontal, and, even though the light is excluded by the closed lids, the pupils are mildly을 constricted (Bender, 1943). On opening the lids the globes return to the midposition and the pupils dilate slightly. Similar ocular and pupil- 0 lary phenomena can be observed during sleep, $\omega$ anaesthesia, and stupor. When the eyelids are? 
closed, the globes are up and divergent and the pupils are constricted. The last example is that induced by electric stimulation of the brain. Stimulation of the tegmentum of the caudal pons or oral medulla in the monkey will produce the triad of associated movements, (1) eyelid closure, (2) upward movement of the globes, and (3) pupillary constriction (Weinstein and Bender, 1943). In the experimental monkey this triad is always bilateral and more prominent on the side of stimulation. As mentioned above, the triad can usually be detected in any of the 10 examples listed in the Table, although the degree of response may vary under different conditions.

Abnormalities of this triad of associated movements may sometimes be observed in disease of the central nervous system in man. One of the most common examples is conjugate deviation of the eyes to the side of a hemiplegia when a patient with a unilateral cerebral lesion attempts to close the eyes forcefully (Cogan, 1948). A similar type of abnormality or horizontal deviation can be observed when the hemiplegic patient falls asleep. Conversely, when the patient becomes alert and opens the lids the eyes move conjugately to the deviated hemiplegic position or to the midposition. It is of interest that the pupillary reactions during the defective conjugate eye movement on eye closure in these cases remain unchanged. A second type of defect of this triad may be observed in patients with lesions of the posterior commissure or both sides of the pretectum. Eye closure in these cases may not be associated with upward movements of the globes or with pupillary constriction (Bender, 1969). Instead, there may be a slight divergence or convergence of the eyes, or a deviation of the eyes to one side. In some of these patients with pretectal lesions there may be spontaneous eyelid retractions and iridoplegia. A third type of defect of this triad may be found in patients with palatal myoclonus produced by a lesion within the dentate nucleus or the central tegmentum fasciculus and affecting the inferior olive in whom eyelid closure may be associated with an upward beat nystagmus of the globes but no pupillary changes. Incidentally, light stimulation in any of the above described pathological conditions fails to evoke abnormal eye movements.

In this communication, we present a variation of ocular response to light stimulation-namely, pupillary light stimulation associated with bilateral rotatory instead of the expected upward movement of the globes.

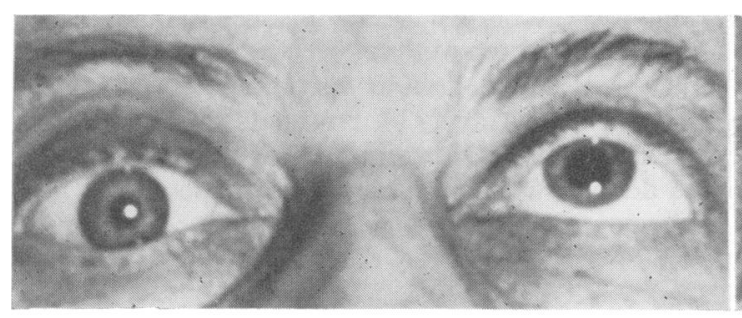

(a)

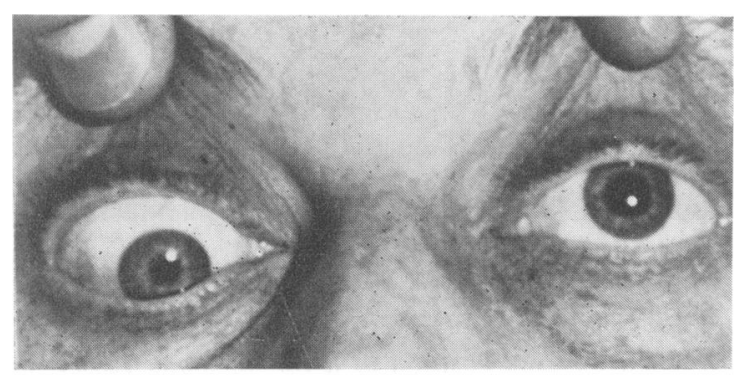

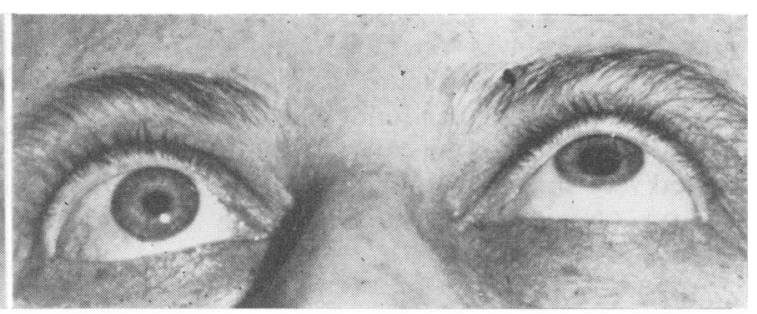

(b)

FIG. 1. Eye movements in the vertical plane. (a) Indicating neutral position of eyes with left pupil measuring $7 \mathrm{~mm}$ and the right $4 \mathrm{~mm}$ in diameter; the left eyeball is situated slightly above the horizontal meridian. (b) Upward gaze. There is slight impairment of movement in O.D., while there is good movement in O.S. (c) Downward gaze. There is good movement in O.D. In O.S. the globe barely moves down to the level of the horizontal meridian.

(c) 
(a)

FIG. 2. Eye movements in the horizontal plane. gaze is normal.

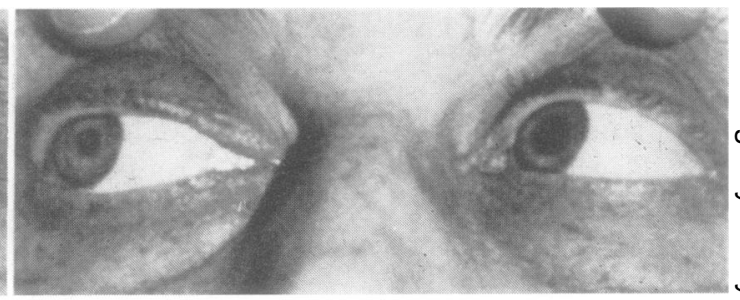

(b)

(a) Left lateral gaze is slightly defective. (b) Right lateral

\section{CASE REPORT}

M.K., a 50 year old female, was admitted to the Mount Sinai Hospital in March 1970, with a two week history of nausea, vomiting, diffuse headache, and diplopia. The double vision appeared suddenly, gradually worsened, and was described as images being vertically separated for all directions of gaze and at near and distant vision. The patient had also been disoriented and amnesic during the week before admission. There had been a left radical mastectomy for carcinoma of the breast in May 1969.

On examination the patient was alert and oriented with no gross abnormalities in the mental status. There was mild ataxia of gait and bilateral ataxia on finger-to-nose and heel-to-knee tests. The deep tendon reflexes were normal and there were no pathological reflexes. Sensation was intact in all respects. There was no facial, palatal, or lingual weakness. The visual acuity was $20 / 30$ bilaterally, uncorrected. The ocular fundi and visual fields were normal. The left pupil was $7 \mathrm{~mm}$ diameter and reacted very sluggishly to direct and consensual light and on attempted convergence. The right pupil measured $4 \mathrm{~mm}$ and reacted better both to direct and के consensual light and in convergence. In the primary $\vec{O}$ position of gaze, there was a left hypertropia slightly worse on gaze to the left and better on gaze to the ${ }_{\sigma}^{\omega}$ right. Horizontal gaze was essentially full with slight limitation of left lateral gaze. On attempted upward gaze, the left eye moved slightly upward but the right $\omega$ eye never moved above the horizontal meridian of (Fig. 1). On attempted downward gaze, the right es moved slightly downward but the left eye never o moved below the horizontal meridian. Convergen was impaired. The corneal reflexes were present, with both eyelids closed there were no gross assoch- $c$ ated movements of the globes. Facial sensations wee intact. Laboratory studies including radiographs $\underset{\overrightarrow{0}}{\overrightarrow{0}}$ the skull with orbital and optic foramen views and pneumoencephalogram were unremarkable.

She was discharged on prednisone, $40 \mathrm{mg}$ per day. However, her condition became slightly worse. There was more double vision and she was re-o admitted on 8 May 1970. Physical examination was unchanged except for some facial rounding. There $\mathscr{\Phi}$ was definite worsening of the left hypertropia. Eye $\vec{\overrightarrow{ }}$ movements were unchanged except that on attempted

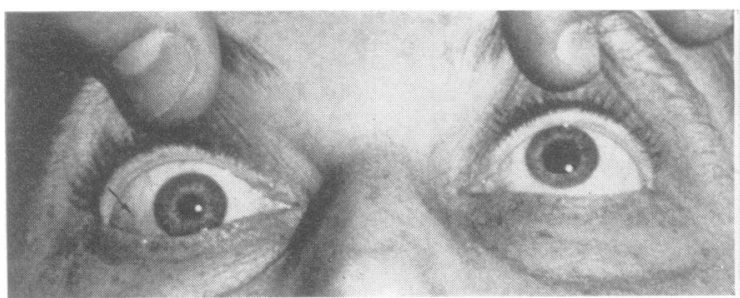

(a)

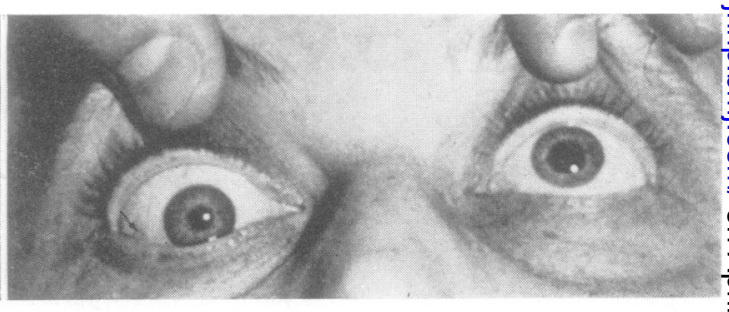

(b)

FIG. 3. Light stimulation causing counterclockwise rotation of the globe in O.D. (a) Before light stimulation. (b) After light stimulation. The arrow at the left in each Figure shows position of a tuft of blood vessels in $\mathrm{w}$ O.D. which rotated to a lower level in (b) 
downward gaze there was downward jerking nystagmus which was more prominent in the right eye (Fig. 2). The clinical diagnosis was a lesion within the brain-stem, probably metastatic. Further and closer observation of the eyes at rest, during spontaneous blinking or on light stimulation, disclosed a torsion movement of the globes instead of slightly upward or no displacement of eyes.

ANALYSIS OF PHENOMENA OF CONJUGATE EYE TORSION ON PUPILLARY LIGHT STIMULATION OR ON EYELID OPENING In this patient volitional eyelid closure was associated with globes moving up and to the right. On eye opening there was immediate pupillary constriction in the right and sluggish in the left eye. In addition, after a 1-2 s delay there was a torsional conjugate movement of both globes. This torsion ocular response was always obtained on light stimulation of either pupil. The eyeball torsion was usually in a counterclockwise direction, and the eyes remained in this rotated position while the light was on (Fig. 3). On occasion, the ocular torsion response to light stimuli was in a clockwise direction. On rare occasions, light stimulation would evoke clockwise movement of the left globe and counterclockwise movement of the right, with a convergence effect. The response of the globes to light could always be obtained on stimulating either pupil. The same effect was also frequently obtained on opening the eyes in a well-illuminated environment. Although the ocular response was bilateral it was not always symmetrical; the eye ipsilateral to the light stimulus moved over a larger arc than the contralateral eye. Conjugate torsional movements of the globes did not occur in attempted convergence with pupillary constriction. There was no torsion during volitional eyelid closure. Neither was there ocular torsion during painful stimulation of the neck or body, nor on instillation of miotic drugs into the conjunctival sac. The torsional movements of the globes on stimulation with light were found consistently and on repeated occasions throughout the period of hospital observation. They were less constant on eyelid opening. On this admission bilateral brachial angiograms revealed slight enlargement of the midbrain characteristic of a mass lesion. The laboratory studies were otherwise unremarkable. The patient failed to reappear for follow-up examination.

\section{DISCUSSION}

The occurrence of torsional conjugate eye movement after eye opening in bright illumination or during pupillary stimulation with light is most unusual. It occurred in a patient who had a demonstrable mass or neoplastic lesion in the brain-stem. This patient also demonstrated abnormal eye movements in the vertical plane. There was marked left hypertropia and on lateral gaze the eyes did not move in a parallel course. This complex of findings has been attributed to lesions of the brain-stem at several levelsnamely, the periaqueductal region, middle cerebellar peduncle, and vestibular nuclei. Abnormalities of vertical gaze may occur with bilateral brain lesions at almost all levels but they are most prominent with lesions of the tegmentum of the brain-stem, particularly the posterior commissure and/or bilateral pretectal regions (Christoff et al., 1962; Pasik et al., 1969a). Monocular elevation paresis, pupillary abnormalities, and impaired convergence have also been described in pretectal lesions (Jampel and Fells, 1968).

Torsional conjugate eye movements induced by light have rarely been observed. Examinations and search for this phenomenon in patients with lesions of the midbrain or brain-stem due to multiple sclerosis, encephalitis, vascular disease, and various neoplasms failed to disclose another such instance. Stimulation of the superior vestibular nucleus or lesions of these nuclei may produce torsional movements in the eyes but they are extremely unusual in other circumstances (Bender and Shanzer, 1964). Torsional eye movement cannot be initiated at will.

Conjugate torsion, in response to pupillary light stimulation, is a defective associated movement and not a synkinesis. The reversenamely, pupillary constriction which occurs with eye movement-is known as a synkinesis. The latter is sometimes found after regeneration of the oculomotor nerve. Thus, pupillary constriction on attempted movement of an affected eye may be observed if the movement is by a muscle innervated by a regenerated nerve. This is a unilateral response and has been attributed to misdirection of regenerating oculomotor fibres (Bender and Fulton, 1939; Bender, 1945). Movements of the globe in response to pupillary light stimulation, however, have not been found in syndromes of ocular nerve regeneration.

It was pointed out that upward eye movements and pupillary constriction may occur during eye closure and that this triad may be induced by a light stimulation of the eye in a normal subject. In our patient, light stimulation produced an ab- 
normal conjugate eye movement in addition to transient eye closure and pupillary constriction. Moreover, when the patient kept the eyes closed for several seconds and then opened them, pupillary constriction and torsion of the eyes occurred. The latter may be explained by stimulation of the pupils with surrounding bright illumination on opening the eyes. It is of interest that, in patients with ocular dyskinesias, light stimulation is known to induce or accentuate these chaotic eye movements (Atkin and Bender, 1964). Induction of ocular dyskinesias with light stimulation has been described in patients with lesions of the pretectal region or in monkeys who had abnormalities of vertical gaze and pupillary light reflexes after experimental lesions in the posterior commissure or bilateral pretectal regions (Pasik et al., 1969b). In such monkeys, light stimulation may precipitate sudden lightning eye movements. However, those fleeting ocular dyskinesias are unlike the torsional sustained conjugate movements observed in our present case.

From the foregoing discussion, it would seem that part of the brain-stem involved in the production of upward movement of the globes is at fault. Whether the pathophysiological mechanisms involve the substrate of the rostral brainstem in the mesencephalic-pretectal regions or the vestibular nuclei, the reticular formation of the tegmentum or some other zones cannot be stated with absolute certainty on the basis of the present evidence.

\section{REFERENCES}

Atkin, A., and Bender, M. B. (1964). 'Lightning eye movements' (ocular myoclonus). Journal of Neurological Science, 1, 2-12.

Bender, M. B. (1943). Eyelid closure reaction. Archives of Ophthalmology, 29, 435-440.

Bender, M. B. (1945). Synkinetic pupillary phenomena and the Argyll Robertson pupil. Archives of Neurology and Psychiatry (Chic.), 53, 418-422.

Bender, M. B. (1969). Disorders of eye movements. In Handbook of Clinical Neurology, vol. 1, pp. 574-630. Edited by P. J. Vinken and G. W. Bruyn. North Holland: Amsterdam.

Bender, M. B., and Fulton, J. F. (1939). Factors in functional recovery following section of the oculomotor nerve in monkeys. Journal of Neurology and Psychiatry, 2, 285-292.

Bender, M. B., and Shanzer, S. (1964). Oculomotor pathways defined by electric stimulation and lesions in the brainstem of monkey. In The Oculomotor System, pp. 81-140. Edited by M. B. Bender. Harper and Row: New York.

Christoff, N., Anderson, P. J., and Bender, M. B. (1962). A clinicopathologic study of associated vertical eye movements. Transactions of the American Neurological Association, 87, 184-186.

Cogan, D. G. (1948). Neurologic significance of laterat conjugate deviation of the eyes on forced closure of th $\overrightarrow{\widehat{B}}$ lids. Archives of Ophthalmology, 39, 37-42.

Jampel, R. S., and Fells, P. (1968). Monocular elevatio paresis caused by a central nervous system lesion. Archiv@ of Ophthalmology, 80, 45-57.

Pasik, P., Pasik, T., and Bender, M. B. (1969a). The pretect. syndrome in monkeys. I. Disturbances of gaze and bode posture. Brain, 92, 521-534.

Pasik, T., Pasik, P., and Bender, M. B. (1969b). The pre tectal syndrome in monkeys. II. Spontaneous and induceđ nystagmus, and 'lightning' eye movements. Brain, 92, 871884

Weinstein, E. A., and Bender, M. B. (1943). Integrated facial patterns elicited by stimulation of the brainstem. Archives of Neurology and Psychiatry (Chic.), 50, 34-42. 